\title{
Adaptive Nonlinear Control for Multi-Tank Level System
}

\author{
Sun Xiuyun ${ }^{*}$
}

School of Mechanical and Electrical Engineering, Dezhou University, Dezhou, Shandong, 253023, P.R. China

\begin{abstract}
For some disturbances and model uncertainties of the multi-tank level system, we developed an adaptive nonlinear control law based on the neural network to achieve high performance control. A nonlinear model including the model uncertainties and disturbances is firstly built through carefully analyzing the multi-tank level system. Based on the model, the level controller is designed, in which the adaptive law based on the neural network is used to approach the model uncertainty and disturbances, and the nonlinear feedback control law deals with the nonlinearity of the multi-tank level system. The proposed control strategy is thoroughly tested by simulation results compared with those obtained from a normal PID controller. The comparisons demonstrate that, for the multi-tank system with the model uncertainty, the designed control strategy is more advantageous in disturbance rejection, with higher control accuracy and so on, and is far superior to the PID control method.
\end{abstract}

Keywords: Adaptive control, multi-tank liquid level system, neural network, nonlinearity.

\section{INTRODUCTION}

Liquid level control is a very important problem in industry processes, such as waterworks, sewage treatment works, petrochemical works, and so on. In these processes, the liquid level is required at a constant value or within a certain range by the level controller. Above complex systems all have the large flow of liquid out, so that the containers are often designed to communicate with each other. Therefore, many scholars have been dedicated to the research on the multi-tank level control and made a number of important achievements [1-7].

Multi-tank system model is the basis of liquid level control. The linear model is used by [1-6], and PID controllers are designed in [2-6] and achieved good performance. However, the complex industry environment causes great difficulties for the accurate system model, and disturbances in the process reduce the quality of the products. So, the model uncertainty and external disturbances are considered in the design of liquid level controller. Therefore, based on manual operation experience, the literature $[7,8]$ has designed the multi-tank system based on fuzzy control and the experiment results show that fuzzy control has better performance than PID. However, it is lack of stability analysis. Multi-tank nonlinear model is adopted by [9], and the nonlinear model predictive controller is designed that the large computation caused by iterative process causes great difficulties with engineering application.

In this paper, considering model uncertainty and disturbances, an adaptive nonlinear multi-tank level controller is designed that make each tank level quickly reach and remain

\footnotetext{
* Address correspondence to this author at the School of Mechanical and Electrical Engineering, Dezhou University, Dezhou, Shandong, 253023, P.R. China; Tel: 18865738009; E-mail: sunxy78@163.com
}

at a constant value. The nonlinear state feedback level controller is designed with nonlinear radial basis function neural network (RBFNN) that approximates model uncertainties and other unknown disturbances, and Lyapunov method that is applied to analyze the stability of the designed system.

\section{DYNAMIC MODEL OF MULTI-TANK SYSTEM}

Fig. (1) depicts the physical structure of multi-tank system. As we know from Fig. (1), only level $h_{1}$ is controlled by a valve, and other levels are all affected by two factors, one of which is the liquid outflow of above its vessel, the other is the corresponding valve opening. Therefore, dynamic mathematical model of multi-tank system is obtained by mechanism analysis.

We firstly analyze the tank 1 , whose liquid inflow $Q_{i 1}$ is controlled by the opening of valve 1 , outflow $Q_{01}$ by the opening of load valve $R_{1}$. Therefore, level $h_{1}$ reflects the liquid balance of tank 1 between inflows and outflows, and the dynamic characteristic of tank 1 is shown as follows:

$\frac{\mathrm{dh}_{1}}{\mathrm{dt}}=\frac{1}{\mathrm{~S}_{1}}\left(\mathrm{Q}_{\mathrm{i} 1}-\mathrm{Q}_{\mathrm{o} 1}\right)$

where $S_{1}$ is the cross-sectional area of tank $1, Q_{i 1}$ is defined by the flow feature of electric control valve:

$\mathrm{Q}_{\mathrm{i} 1}=\mathrm{k}_{\mathrm{u} 1} \mathrm{u}_{1}$

where $Q_{i 1}$ is equal percentage flow characteristic, $k_{\mathrm{u} 1}$ is the flow coefficients of electric valve 1 , and $\mathrm{u}_{1}$ is the opening. Load valve $R_{1}$ is regulated by the operating person. When the opening of the valve $R_{1}$ is a constant, its structure cannot vary, and the outflow $Q_{01}$ is denoted as:

$\mathrm{Q}_{\mathrm{o} 1}=\mathrm{k}_{1} \sqrt{\mathrm{h}_{1}}$ 


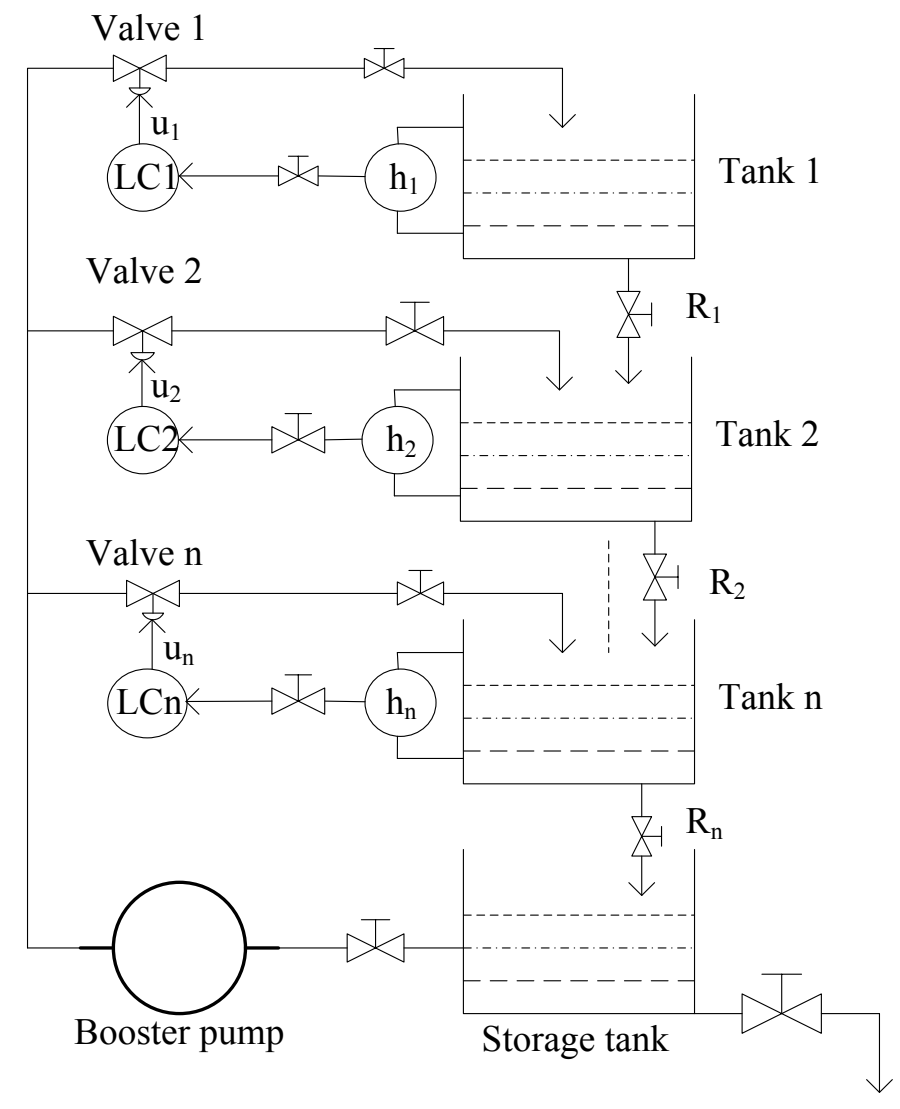

Fig. (1). Schematic diagram of multi-tank system.

where $\mathrm{k}_{1}$ is the flow coefficient. Bring Eq. (2) and Eq. (3) into Eq. (1), the dynamics model of level $h_{1}$ is obtained:

$\frac{\mathrm{dh}_{1}}{\mathrm{dt}}=\frac{1}{\mathrm{~s}_{1}}\left(\mathrm{Q}_{\mathrm{i} 1}-\mathrm{Q}_{\mathrm{o} 1}\right)=\frac{1}{\mathrm{~s}_{1}}\left(\mathrm{k}_{\mathrm{u} 1} \mathrm{u}_{1}-\mathrm{k}_{1} \sqrt{\mathrm{h}_{1}}\right)$

$=\mathrm{a}_{1} \sqrt{\mathrm{h}_{1}}+\mathrm{b}_{1} \mathrm{u}_{1}$

where $a_{1}=-\frac{k_{1}}{s_{1}}$ and $b_{1}=\frac{k_{u 1}}{s_{1}}$.

Secondly, we analyze the tank 2 , whose level $h_{2}$ is affected by the inflow of valve $2 Q_{\mathrm{i} 2}=\mathrm{k}_{\mathrm{u} 2} \mathrm{u}_{2}$ and the outflow of tank $1 \mathrm{Q}_{\mathrm{o} 1}$ and tank $2 \mathrm{Q}_{\mathrm{o} 2}=\mathrm{k}_{2} \sqrt{\mathrm{h}_{2}}$, where $\mathrm{k}_{\mathrm{u} 2}$ and $\mathrm{u}_{2}$ are the flow coefficient and opening of valve 2 , respectively, $\mathrm{k}_{2}$ is the flow coefficient of load valve $\mathrm{R}_{2}$. As used in the same analysis method with the tank, the dynamics of level $\mathrm{h}_{2}$ is obtained as:

$\frac{\mathrm{dh}_{2}}{\mathrm{dt}}=\frac{1}{\mathrm{~S}_{2}}\left(\mathrm{Q}_{\mathrm{i} 2}+\mathrm{Q}_{\mathrm{o} 1}-\mathrm{Q}_{\mathrm{o} 2}\right)$

$=\frac{1}{\mathrm{~s}_{2}}\left(\mathrm{k}_{\mathrm{u} 2} \mathrm{u}_{2}+\mathrm{k}_{1} \sqrt{\mathrm{h}_{1}}-\mathrm{k}_{2} \sqrt{\mathrm{h}_{2}}\right)$

$=\mathrm{a}_{12} \sqrt{\mathrm{h}_{1}}+\mathrm{a}_{2} \sqrt{\mathrm{h}_{2}}+\mathrm{b}_{2} \mathrm{u}_{2}$

where $\mathrm{a}_{12}=\frac{\mathrm{k}_{1}}{\mathrm{~s}_{2}}, \mathrm{a}_{2}=-\frac{\mathrm{k}_{2}}{\mathrm{~s}_{2}}, \mathrm{~b}_{2}=-\frac{\mathrm{k}_{\mathrm{u} 2}}{\mathrm{~s}_{2}}$.

Then, we adopt the above analysis method with the tank $\mathrm{n}$, the dynamics of $\mathrm{h}_{\mathrm{k}}$ for the tank $\mathrm{k}$ is obtained:

$$
\begin{aligned}
& \frac{\mathrm{dh}_{\mathrm{n}}}{\mathrm{dt}}=\frac{1}{\mathrm{~S}_{\mathrm{n}}}\left(\mathrm{Q}_{\text {in }}+\mathrm{Q}_{\mathrm{o}(\mathrm{n}-1)}-\mathrm{Q}_{\mathrm{on}}\right) \\
& =\frac{1}{\mathrm{~S}_{\mathrm{n}}}\left(\mathrm{k}_{\mathrm{un}} \mathrm{u}_{\mathrm{n}}+\mathrm{k}_{\mathrm{n}-1} \sqrt{\mathrm{h}_{\mathrm{n}-1}}-\mathrm{k}_{\mathrm{n}} \sqrt{\mathrm{h}_{\mathrm{n}}}\right) \\
& =\mathrm{a}_{(\mathrm{n}-1) \mathrm{n}} \sqrt{\mathrm{h}_{\mathrm{n}}}+\mathrm{a}_{\mathrm{n}} \sqrt{\mathrm{h}_{\mathrm{n}}}+\mathrm{b}_{\mathrm{n}} \mathrm{u}_{\mathrm{n}}
\end{aligned}
$$

where $h_{n}$ is the level of tank $n, S_{n}$ is the cross-sectional area of tank $\mathrm{n}$, the inflow controlled by valve $\mathrm{n}$ is $\mathrm{Q}_{\mathrm{in}}=$ $\mathrm{k}_{\mathrm{un}} \mathrm{u}_{\mathrm{n}}, \mathrm{k}_{\mathrm{un}}$ and $\mathrm{u}_{\mathrm{n}}$ are the flow coefficient and opening of valve $n$, the outflow of tank $n$ is $Q_{o n}=k_{n} \sqrt{h_{n}}, k_{n}$ is the flow coefficient of load valve $R_{n}$ and $a_{(n-1) n}=\frac{k_{n-1}}{s_{n}}$ $a_{n}=-\frac{k_{n}}{s_{n}}, b_{n}=-\frac{k_{u n}}{s_{n}}$.

The above analysis suggests that multi-tank system has nonlinearity and great coupling between each tank. Additionally, in the actual industry process, the levels of multitank system are also influenced by the fluid viscosity, density, temperature and other working conditions. Moreover, the flow characteristics of valve are not entirely linear. So, the above multi-tank system model ignores some model uncertainty and interferences that should be considered in the design of multi-tank control system. Lastly, on the basis of the above ideal model, considering the model uncertainties and external disturbances, the level dynamic of multi-tank system is as follows: 


$$
\begin{gathered}
\dot{\mathrm{h}}_{1}=\mathrm{a}_{1} \sqrt{\mathrm{h}_{1}}+\mathrm{b}_{1} \mathrm{u}_{1}+\Delta_{1}+\mathrm{d}_{1} \\
\dot{\mathrm{h}}_{2}=\mathrm{a}_{12} \sqrt{\mathrm{h}_{1}}+\mathrm{a}_{2} \sqrt{\mathrm{h}_{2}}+\mathrm{b}_{2} \mathrm{u}_{2}+\Delta_{2}+\mathrm{d}_{2} \\
\vdots \\
\dot{\mathrm{h}}_{\mathrm{n}}=\mathrm{a}_{(\mathrm{n}-1) \mathrm{n}} \sqrt{\mathrm{h}_{\mathrm{n}}}+\mathrm{a}_{\mathrm{n}} \sqrt{\mathrm{h}_{\mathrm{n}}}+\mathrm{b}_{\mathrm{n}} \mathrm{u}_{\mathrm{n}}+\Delta_{\mathrm{n}}+\mathrm{d}_{\mathrm{n}}
\end{gathered}
$$

where $\Delta_{i}(\mathrm{i}=1,2, \ldots, \mathrm{n})$ is the model uncertainty, $\mathrm{d}_{\mathrm{i}}$ is the disturbance and $\left|\mathrm{d}_{\mathrm{i}}\right|<\mathrm{d}_{\text {max }}$.

The control objective is to keep the desired liquid level of multi-tank system in the presence of model uncertainty and environmental disturbance. Thus, the proposed level control techniques must render each tank track with a desired level $h_{\text {id }}$ such that the tracking errors converge to a very small neighborhood of the origin, that is, $\lim _{\mathrm{t} \rightarrow \infty}\left|\mathrm{h}_{\mathrm{i}}-\mathrm{h}_{\mathrm{id}}\right|<$ $\varepsilon$ with $\varepsilon>0$. To facilitate control system design, we assume that all levels of the multi-tank system dynamics (7) are available. Moreover, the following assumptions are needed for the subsequent developments.

Assumption 1: For all $\mathrm{t}>0$, there exist $\sigma_{\mathrm{i}}>0$ such that $\left|\dot{\mathrm{h}}_{\mathrm{id}}\right| \leq \sigma_{\mathrm{i}}$.

Lemma 1: For bounded initial conditions, if there exists a $\mathrm{C}^{1}$ continuous and positive definite Lyapunov function $\mathrm{V}(\mathrm{x})$ satisfying $\mu_{1}(\|\mathrm{x}\|) \leq \mathrm{V}(\mathrm{x}) \leq \mu_{2}(\|\mathrm{x}\|)$, such that $\dot{\mathrm{V}}(\mathrm{x}) \leq-\tau \mathrm{V}(\mathrm{x})+\mathrm{c}$, where $\mu_{1}, \mu_{2}: \mathcal{R}^{\mathrm{n}} \rightarrow \mathcal{R}$ are class $\mathrm{K}$ functions and $\mathrm{c}$ is a positive constant, then the solution $\mathrm{x}(\mathrm{t})$ is uniformly bounded.

\section{NONLIEAR ADAPTIVE CONTROLLER DESIGN}

This section will design the nonlinear adaptive controller for the multi-tank system. The control strategy uses RBFNN to approximate model uncertainties and unknown interferences and nonlinear feedback control method to deal with nonlinearity and coupling. Lyapunov theory analysis of the designed control system shows that the controller will enable the level of multi-tank system to quickly arrive at its set value.

\subsection{Adaptive Control Law Design}

For tank $\mathrm{i}$, supposing that $\mathrm{h}_{\mathrm{id}}$ is its liquid level setting point, and then the level error is $e_{i}=h_{i}-h_{i d}(i=1,2, \ldots, n)$. Defining the unknown item $\Delta_{i}+d_{i}$ of model (7) is $\rho\left(e_{i}\right)$ which is approximated with RBFNNs and expressed as [10]:

$\hat{\rho}\left(\mathrm{e}_{\mathrm{i}}\right)=\widehat{\boldsymbol{\theta}}_{\mathrm{i}}^{\mathrm{T}} \mathrm{S}\left(\mathrm{e}_{\mathrm{i}}\right)$

where $\widehat{\boldsymbol{\theta}}_{\mathrm{i}} \in \mathrm{R}^{\mathrm{L} \times 1}$ is the approximation parameter, $\mathrm{S}\left(\mathrm{e}_{\mathrm{i}}\right)=\left[\mathrm{s}_{1}\left(\mathrm{e}_{\mathrm{i}}\right), \mathrm{s}_{2}\left(\mathrm{e}_{\mathrm{i}}\right), \cdots \mathrm{s}_{\mathrm{l}}\left(\mathrm{e}_{\mathrm{i}}\right)\right] \in \mathrm{R}^{\mathrm{L} \times 1}$ represents the basis function vector with $N N$ node number $L>1$ and $s_{k}\left(e_{i}\right)$ is chosen as the commonly used Gaussian distribution:

$\mathrm{s}_{\mathrm{k}}\left(\mathrm{e}_{\mathrm{i}}\right)=\exp \left(\frac{\left|\mathrm{e}_{\mathrm{i}}-\mathrm{c}_{\mathrm{ik}}\right|^{2}}{\sigma_{\mathrm{ik}}^{2}}\right), \mathrm{k}=1,2, \ldots, \mathrm{L}$

where $c_{i k}$ is the center of receptive field and $\sigma_{i k}$ is the width of the Gaussian function. $\widehat{\boldsymbol{\theta}}_{\mathrm{i}}^{\mathrm{T}} \mathrm{S}\left(\mathrm{e}_{\mathrm{i}}\right)$ approximates $\boldsymbol{\theta}_{\mathrm{i}}^{* \mathrm{~T}} \mathrm{~S}\left(\mathrm{e}_{\mathrm{i}}\right)$ and is given by: $\boldsymbol{\theta}_{\mathrm{i}}^{* \mathrm{~T}} \mathrm{~S}\left(\mathrm{e}_{\mathrm{i}}\right)+\varepsilon_{\mathrm{i}}=\rho\left(\mathrm{e}_{\mathrm{i}}\right)$

where $\boldsymbol{\theta}_{\mathrm{i}}^{*}$ is the most optimal weight vector and obtained by solving the following optimization problem:

$$
\boldsymbol{\theta}_{\mathrm{i}}^{*}=\arg \min _{\boldsymbol{\theta}_{\mathrm{i}}^{*} \in \mathrm{R}^{\mathrm{L} \times 1}}\left(\sup \left|\widehat{\boldsymbol{\theta}}_{\mathrm{i}}^{\mathrm{T}} \mathrm{S}\left(\mathrm{e}_{\mathrm{i}}\right)-\rho\left(\mathrm{e}_{\mathrm{i}}\right)\right|\right)
$$

and $\varepsilon_{\mathrm{i}}<\varepsilon_{\max }$ is the approximation error with and $\varepsilon_{\max }$ is the upper bound of approximation error. The control law for $\widehat{\boldsymbol{\theta}}_{\mathrm{i}}$ is designed as:

$\dot{\hat{\boldsymbol{\theta}}}_{\mathrm{i}}=\Gamma_{\mathrm{i}}\left[\mathrm{e}_{\mathrm{i}} \mathrm{S}\left(\mathrm{e}_{\mathrm{i}}\right)-\lambda_{\mathrm{i}}\left(\widehat{\boldsymbol{\theta}}_{\mathrm{i}}-\widehat{\boldsymbol{\theta}}_{\mathrm{i} 0}\right)\right]$

where $\Gamma_{\mathrm{i}} \in \mathrm{R}^{\mathrm{L} \times \mathrm{L}}$ is positive definite diagonal matrix, $\hat{\theta}_{\mathrm{i} 0}$ is the initial weight value and the $\lambda_{\mathrm{i}}>0$ is the correction coefficient which increases the robustness of NN approximation error and reduces the effect of parameter drift.

\subsection{Nonlinear Controller Design}

For the first equation of multi-tank model (7), the opening of valve $1 \mathrm{u}_{1}$ is designed as:

$\mathrm{u}_{1}=-\frac{1}{\mathrm{~b}_{1}}\left[\mathrm{a}_{1} \sqrt{\mathrm{h}_{1}}+\mathrm{k}_{1} \mathrm{e}_{1}+\widehat{\theta}_{1}^{\mathrm{T}} \mathrm{S}\left(\mathrm{e}_{1}\right)+\dot{\mathrm{h}}_{1 \mathrm{~d}}\right]$

where $\mathrm{k}_{1}>0$ is the control gain. The opening of valve $2 \mathrm{u}_{2}$ is designed as:

$\mathrm{u}_{2}=-\frac{1}{\mathrm{~b}_{2}}\left[\mathrm{a}_{12} \sqrt{\mathrm{h}_{1}}+\mathrm{a}_{2} \sqrt{\mathrm{h}_{2}}+\mathrm{k}_{2} \mathrm{e}_{2}+\hat{\theta}_{2}^{\mathrm{T}} \mathrm{S}\left(\mathrm{e}_{2}\right)+\dot{\mathrm{h}}_{2 \mathrm{~d}}\right]$

where $\mathrm{k}_{2}>0$ is the control gain. Similarly, The opening of valve $i u_{i}$ is designed as:

$\mathrm{u}_{\mathrm{i}}=-\frac{1}{\mathrm{~b}_{\mathrm{i}}}\left[\mathrm{a}_{(\mathrm{i}-1) \mathrm{i}} \sqrt{\mathrm{h}_{\mathrm{i}}}+\mathrm{a}_{\mathrm{i}} \sqrt{\mathrm{h}_{\mathrm{i}}}+\mathrm{k}_{\mathrm{i}} \mathrm{e}_{\mathrm{i}}+\widehat{\theta}_{\mathrm{i}}^{\mathrm{T}} \mathrm{S}\left(\mathrm{e}_{\mathrm{i}}\right)+\dot{\mathrm{h}}_{\mathrm{id}}\right]$

where $\mathrm{k}_{\mathrm{i}}>0$ is the control gain.

\section{STABILITY ANALYSIS}

Theorem 1: Consider the multi-tank system dynamics (7) satisfies the Assumptions 1. The robust level controller is designed according to (14) using NNs and parameter updated law is chosen as (11). For bounded initial conditions, there exist design parameters $\Gamma_{\mathrm{i}}=\Gamma_{\mathrm{i}}^{\mathrm{T}}>0, \mathrm{k}_{\mathrm{i}}>0$ and $\lambda_{\mathrm{i}}>0$ such that the overall closed-loop control system is semi-globally stable in the sense that all of the closed-loop signals $e_{i}$ and $\widetilde{\theta}_{i}$ are bounded. Furthermore, the tracking error $e_{i}$ converges to a compact set.

Proof: Let $\widetilde{\theta}_{i}=\widehat{\theta}_{i}-\theta_{i}^{*}$ is the weight vector estimation error. Substituting the first equation of model (7), unknown items approximation (8) and controller (12) into the time differentiation of the level error $\mathrm{e}_{1}$, the closed system dynamics of tank 1 is as follows:

$\dot{\mathrm{e}}_{1}=\dot{\mathrm{h}}_{1}-\dot{\mathrm{h}}_{1 \mathrm{~d}}=-\mathrm{k}_{1} \mathrm{e}_{1}-\widetilde{\theta}_{1}^{\mathrm{T}} \mathrm{S}\left(\mathrm{e}_{1}\right)+\varepsilon_{1}$

Choose the Lyapunov function candidate:

$\mathrm{V}_{1}=\frac{1}{2} \mathrm{e}_{1}^{2}+\frac{1}{2} \widetilde{\theta}_{1}^{\mathrm{T}} \Gamma_{1}^{-1} \widetilde{\theta}_{1}$ by:

Owing to (15) and (10), the time derivative of $V_{1}$ is given 


$$
\begin{aligned}
\dot{\mathrm{V}}_{1}=\mathrm{e}_{1} \dot{\mathrm{e}}_{1}+\widetilde{\theta}_{1}^{\mathrm{T}} \Gamma_{1}^{-1} \dot{\hat{\theta}}_{1}=\mathrm{e}_{1}\left(-\mathrm{k}_{1} \mathrm{e}_{1}-\widetilde{\theta}_{1}^{\mathrm{T}} \mathrm{S}\left(\mathrm{e}_{1}\right)+\varepsilon_{1}\right) \\
+\tilde{\theta}_{1}^{\mathrm{T}} \Gamma_{1}^{-1}\left(\Gamma_{1}\left[\mathrm{e}_{1} \mathrm{~S}\left(\mathrm{e}_{1}\right)-\lambda_{1}\left(\hat{\theta}_{1}-\hat{\theta}_{10}\right)\right]\right)-\mathrm{k}_{1} \mathrm{e}_{1}^{2} \\
+\mathrm{e}_{1} \varepsilon_{1}-\tilde{\theta}_{1}^{\mathrm{T}} \lambda_{1}\left(\hat{\theta}_{1}-\hat{\theta}_{10}\right)
\end{aligned}
$$

Noting the following facts:

$\mathrm{e}_{1} \varepsilon_{1} \leq \frac{1}{2} \mathrm{e}_{1}^{2}+\frac{1}{2} \varepsilon_{1}^{2}$

$-\tilde{\theta}_{1}^{\mathrm{T}} \lambda_{1}\left(\hat{\theta}_{1}-\hat{\theta}_{10}\right)=-\tilde{\theta}_{1}^{\mathrm{T}} \lambda_{1}\left(\tilde{\theta}_{1}+\theta_{1}^{*}-\hat{\theta}_{10}\right)$

$-\frac{1}{2} \lambda_{1}\left\|\tilde{\theta}_{1}\right\|^{2}+\frac{1}{2} \lambda_{1}\left\|\theta_{1}^{*}-\hat{\theta}_{10}\right\|^{2}$

We obtain,

$\dot{\mathrm{V}}_{1} \leq-\left(\mathrm{k}_{1}-\frac{1}{2}\right) \mathrm{e}_{1}^{2}-\frac{1}{2} \lambda_{1}\left\|\tilde{\theta}_{1}\right\|^{2}+\frac{1}{2} \varepsilon_{1}^{2}+\frac{1}{2} \lambda_{1}\left\|\theta_{1}^{*}-\hat{\theta}_{10}\right\|^{2}$

$\leq-2 \mathrm{r}_{1}\left(\frac{1}{2} \mathrm{e}_{1}^{2}+\frac{1}{2} \tilde{\theta}_{1}^{\mathrm{T}} \Gamma_{1}^{-1} \tilde{\theta}_{1}\right)+\mathrm{C}_{1}$

where $\quad 0<\mathrm{r}_{1}<\min \left(\left(\mathrm{k}_{1}-\frac{1}{2}\right), \frac{\lambda_{1}}{\lambda_{\max }\left(\Gamma_{1}^{-1}\right)}\right), \mathrm{C}_{1}=\frac{1}{2} \varepsilon_{1}^{2}+$ $\frac{1}{2} \lambda_{1}\left\|\theta_{1}^{*}-\hat{\theta}_{10}\right\|^{2}$. To ensure that $r_{1}>0$, the design parameter $\mathrm{k}_{1}>\frac{1}{2}$.

Substituting the second equation of model (7), unknown items approximation (8) and controller (13) into the time differentiation of the level error $\mathrm{e}_{2}$, the closed system dynamics of tank 2 is as follows:

$\dot{\mathrm{e}}_{2}=\dot{\mathrm{h}}_{2}-\dot{\mathrm{h}}_{2 \mathrm{~d}}=-\mathrm{k}_{2} \mathrm{e}_{2}-\tilde{\theta}_{2}^{\mathrm{T}} \mathrm{S}\left(\mathrm{e}_{2}\right)+\varepsilon_{2}$

Consider the Lyapunov function candidate:

$\mathrm{V}_{2}=\frac{1}{2} \mathrm{e}_{2}^{2}+\frac{1}{2} \widetilde{\theta}_{2}^{\mathrm{T}} \Gamma_{2}^{-1} \widetilde{\theta}_{2}$

Using the similar analysis method as tank 1 , the time derivative of $V_{2}$ is:

$\dot{\mathrm{V}}_{2} \leq-\left(\mathrm{k}_{2}-\frac{1}{2}\right) \mathrm{e}_{2}^{2}-\frac{1}{2} \lambda_{2}\left\|\tilde{\theta}_{2}\right\|^{2}+\frac{1}{2} \varepsilon_{2}^{2}+\frac{1}{2} \lambda_{2}\left\|\theta_{2}^{*}-\hat{\theta}_{20}\right\|^{2}$

$\leq-2 \mathrm{r}_{2}\left(\frac{1}{2} \mathrm{e}_{2}^{2}+\frac{1}{2} \tilde{\theta}_{2}^{\mathrm{T}} \Gamma_{2}^{-1} \widetilde{\theta}_{2}\right)+\mathrm{C}_{2}$

Where $0<\mathrm{r}_{2}<\min \left(\left(\mathrm{k}_{2}-\frac{1}{2}\right), \frac{\lambda_{2}}{\lambda_{\max }\left(\Gamma_{2}^{-1}\right)}\right), \quad \mathrm{C}_{2}=\frac{1}{2} \varepsilon_{2}^{2}+$ $\frac{1}{2} \lambda_{2}\left\|\theta_{2}^{*}-\hat{\theta}_{20}\right\|^{2}$. To ensure that $r_{2}>0$, the design parameter $\mathrm{k}_{2}>\frac{1}{2}$.

Similarly, substituting the i-th equation of model (7), unknown items approximation (8) and controller (14) into the time differentiation of the level error $\mathrm{e}_{\mathrm{i}}$, the closed system dynamics of tank $i$ is as follows:

$\dot{\mathrm{e}}_{\mathrm{i}}=\dot{\mathrm{h}}_{\mathrm{i}}-\dot{\mathrm{h}}_{\mathrm{id}}=-\mathrm{k}_{\mathrm{i}} \mathrm{e}_{\mathrm{i}}-\widetilde{\theta}_{\mathrm{i}}^{\mathrm{T}} \mathrm{S}\left(\mathrm{e}_{\mathrm{i}}\right)+\varepsilon_{\mathrm{i}}$

Consider the Lyapunov function candidate:

$\mathrm{V}_{\mathrm{i}}=\frac{1}{2} \mathrm{e}_{\mathrm{i}}^{2}+\frac{1}{2} \tilde{\theta}_{\mathrm{i}}^{\mathrm{T}} \Gamma_{\mathrm{i}}^{-1} \tilde{\theta}_{\mathrm{i}}$

Similar as tank 1 , we obtain:

$$
\dot{\mathrm{V}}_{\mathrm{l}} \leq-\left(\mathrm{k}_{\mathrm{i}}-\frac{1}{2}\right) \mathrm{e}_{\mathrm{i}}^{2}-\frac{1}{2} \lambda_{\mathrm{i}}\left\|\tilde{\theta}_{\mathrm{i}}\right\|^{2}+\frac{1}{2} \varepsilon_{\mathrm{i}}^{2}+\frac{1}{2} \lambda_{\mathrm{i}}\left\|\theta_{\mathrm{i}}^{*}-\widehat{\theta}_{\mathrm{i} 0}\right\|^{2}
$$

$\leq-2 \mathrm{r}_{\mathrm{i}}\left(\frac{1}{2} \mathrm{e}_{\mathrm{i}}^{2}+\frac{1}{2} \widetilde{\theta}_{\mathrm{i}}^{\mathrm{T}} \Gamma_{\mathrm{i}}^{-1} \widetilde{\theta}_{\mathrm{i}}\right)+\mathrm{C}_{\mathrm{i}}$

where $0<\mathrm{r}_{\mathrm{i}}<\min \left(\left(\mathrm{k}_{\mathrm{i}}-\frac{1}{2}\right), \frac{\lambda_{\mathrm{i}}}{\lambda_{\max }\left(\Gamma_{\mathrm{i}}^{-1}\right)}\right) \quad, \quad \mathrm{C}_{\mathrm{i}}=\frac{1}{2} \varepsilon_{\mathrm{i}}^{2}+$ $\frac{1}{2} \lambda_{\mathrm{i}}\left\|\theta_{\mathrm{i}}^{*}-\hat{\theta}_{\mathrm{i} 0}\right\|^{2}$. To ensure that $\mathrm{r}_{\mathrm{i}}>0$, the design parameter $\mathrm{k}_{\mathrm{i}}>\frac{1}{2}$.

For the multi-tank system, the augmented Lyapunov function candidate can be written as:

$\mathrm{V}=\sum_{\mathrm{i}=1}^{\mathrm{n}} \mathrm{V}_{\mathrm{i}}$

Considering inequality (20), (23) and (26), the time derivative of $\mathrm{V}$ yields :

$$
\dot{\mathrm{V}}=\sum_{\mathrm{i}=1}^{\mathrm{n}} \dot{\mathrm{V}}_{\mathrm{l}} \leq \sum_{\mathrm{i}=1}^{\mathrm{n}}\left[-2 \mathrm{r}_{\mathrm{i}}\left(\frac{1}{2} \mathrm{e}_{\mathrm{i}}^{2}+\frac{1}{2} \tilde{\theta}_{\mathrm{i}}^{\mathrm{T}} \Gamma_{\mathrm{i}}^{-1} \tilde{\theta}_{\mathrm{i}}\right)+\mathrm{C}_{\mathrm{i}}\right]
$$

$\leq-2 \mathrm{rV}+\mathrm{C}$

where $0<r<\min \left(\mathrm{r}_{1}, \mathrm{r}_{2}, \ldots, \mathrm{r}_{\mathrm{n}}\right), \mathrm{C}=\sum_{\mathrm{i}=1}^{\mathrm{n}} \mathrm{C}_{\mathrm{i}}$. Multiplying (28) by $\mathrm{e}^{-2 \mathrm{rt}}$ and integrating over $[0, \mathrm{t}]$, we obtain:

$0 \leq \mathrm{V}(\mathrm{t}) \leq \frac{\mathrm{C}}{2 \mathrm{r}}+\left(\mathrm{V}(0)-\frac{\mathrm{C}}{2 \mathrm{r}}\right) \mathrm{e}^{-2 \mathrm{rt}}$

According to (29), we can prove the bounded stability of the closed-loop system if only appropriate design tersk $_{\mathrm{i}}$ and $\lambda_{\mathrm{i}}$ are chosen. Therefore all signals of the closedloop system, that is, $e_{i}$ and $\tilde{\theta}_{i}$ are uniformly ultimately bounded and the tracking error $\mathrm{e}_{\mathrm{i}}$ converges to the compact set $\Omega_{\mathrm{e}_{\mathrm{i}}}:=\left\{\mathrm{e}_{\mathrm{i}} \in \mathrm{R} \mid \mathrm{e}_{\mathrm{i}}<\alpha\right\}$ where $\alpha=2\left(\mathrm{~V}(0)+\frac{\mathrm{C}}{2 \mathrm{r}}\right), \mathrm{C}$ and $\mathrm{r}$ are defined in (28).

This concludes the proof.

\section{SIMULATION RESULTS}

A two-tank system is used in this section, whose model is built in MATLAB/Simulink and then simulations are given to demonstrate the effectiveness of the proposed level control techniques. In this simulation, the model uncertainties and external disturbances are considered, and then the dynamics of two-tank system is expressed as :

$$
\begin{aligned}
& \dot{\mathrm{h}}_{1}=-0.5 \sqrt{\mathrm{h}_{1}}+0.04 \mathrm{u}_{1}+\Delta_{1}+\mathrm{d}_{1} \\
& \dot{\mathrm{h}}_{2}=0.4 \sqrt{\mathrm{h}_{1}}-0.2 \sqrt{\mathrm{h}_{2}}+0.03 \mathrm{u}_{2}+\Delta_{2}+\mathrm{d}_{2}
\end{aligned}
$$

where the model uncertainties are given by:

$\Delta_{1}=\Delta_{2}=0.5 \cdot \sin (20 \pi \cdot \mathrm{t}) \mathrm{m}$

and external disturbances are the white noises with the maximum amplitude $\mathrm{d}_{\max }=0.5 \mathrm{~m}$.

The control gains are chosen as $\mathrm{k}_{1}=2$ and $\mathrm{k}_{2}=3$, neural network parameters are: $\mathrm{L}=3, \mathrm{c}_{\mathrm{i} 1}=-0.5, \mathrm{c}_{\mathrm{i} 2}=0, \mathrm{c}_{\mathrm{i} 2}=$ 0.5 , and $\sigma_{\mathrm{i} 1}=\sigma_{\mathrm{i} 2}=\sigma_{\mathrm{i} 3}=1(\mathrm{i}=1,2)$ and the adaptive update law parameters are: $\Gamma_{1}=\Gamma_{2}=\operatorname{diag}(0.5,0.5,0.5)$, $\lambda_{1}=\lambda_{2}=0.1$.

For further highlighting the performance of the proposed control algorithm, which is in contrast with PID control. The 


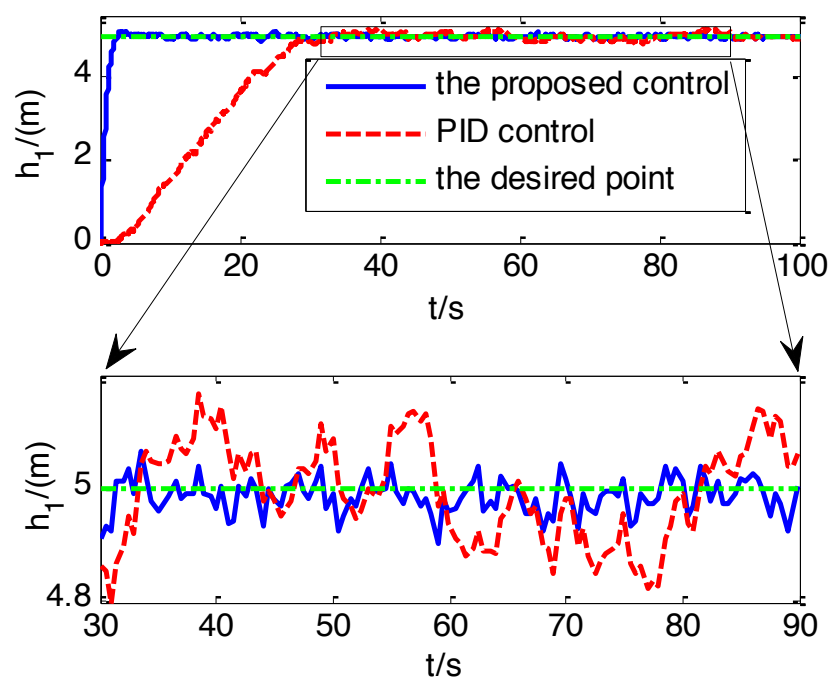

Fig. (2). The simulation results of liquid level 1.

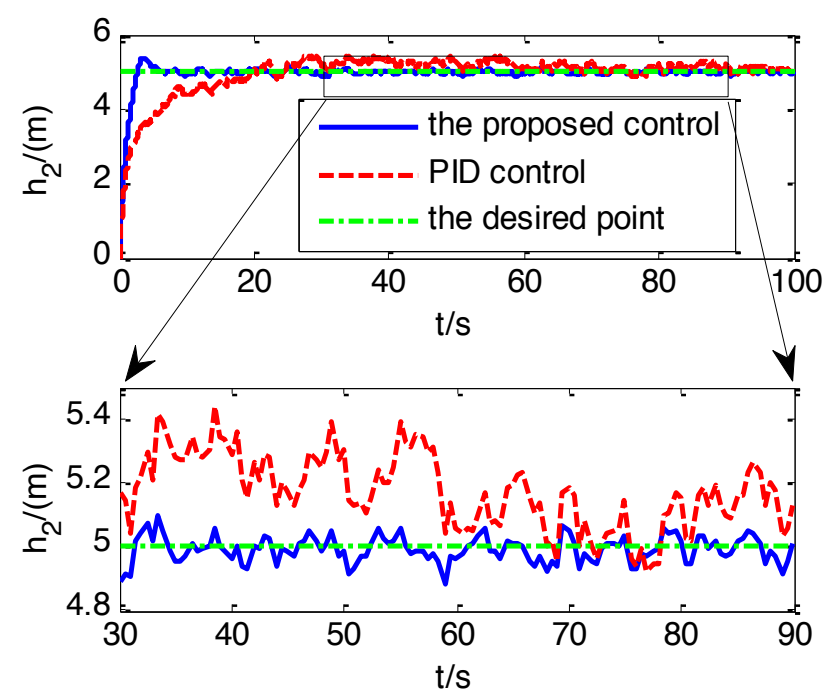

Fig. (3). The simulation results of liquid level 2.

control parameters of first tank are chosen as: $\mathrm{K}_{\mathrm{p} 1}=$ $2, \mathrm{~K}_{\mathrm{i} 1}=0.6$, and the second tank are $\mathrm{K}_{\mathrm{p} 2}=10, \mathrm{~K}_{\mathrm{i} 2}=0.2$.

We suppose the initial states of a two-tank system are:

$\mathrm{h}_{10}=\mathrm{h}_{20}=0 \mathrm{~m}$,

and the control objectives are

$\mathrm{h}_{1 \mathrm{~d}}=\mathrm{h}_{2 \mathrm{~d}}=5 \mathrm{~m}$.

The simulation results are given in Figs. (2-4). Fig. (2) and Fig. (3) show the level $\mathrm{h}_{1}$ and level $\mathrm{h}_{2}$, in which dotted dashes line shows the desired value, solid line is the proposed control and dashes line is PID control. Fig. (4) shows the control signals of valve $1 \mathrm{u}_{1}$ and valve $2 \mathrm{u}_{2}$.

From Fig. (2) and Fig. (3), the level of both two-tank systems can be maintained within a small envelop of the desired point with the uncertainties and disturbances. However, for the designed adaptive nonlinear control system, two level steady errors are within $\pm 0.1 \mathrm{~m}$, while two errors of the PID control system are within $\pm 0.2 \mathrm{~m}$ and $\pm 0.6 \mathrm{~m}$, separately. It is concluded that the adaptive nonlinear control strategy has better performance than PID control.

\section{CONCLUSION}

In this paper, the adaptive nonlinear control has been presented for multi-tank system in the presence of model uncertainty and unknown disturbance. In the proposed control techniques, the nonlinear dynamics have been considered and the semi-globally uniform boundedness of the closedloop signals has been guaranteed via Lyapunov analysis. Finally, simulation studies have been provided to illustrate the effectiveness of the proposed level control. In the subsequent research, we will use the adaptive nonlinear control in the practical engineering to further test its performance. 

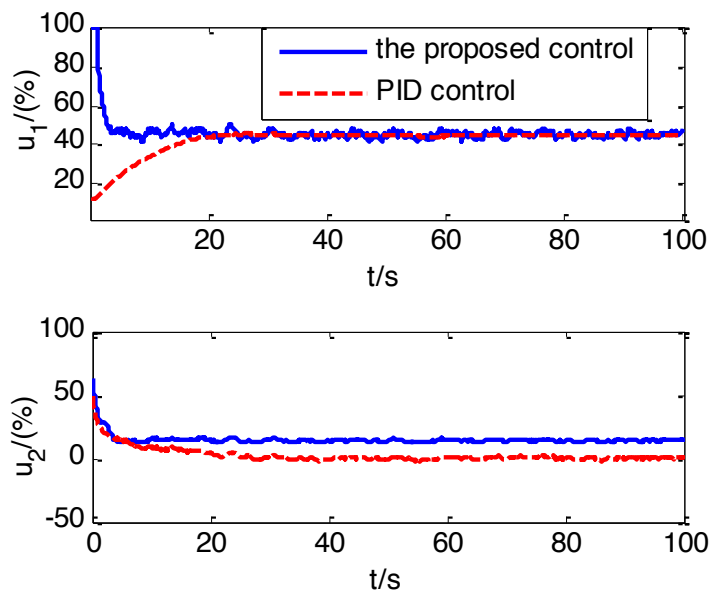

Fig. (4). The control signals.

\section{CONFLICT OF INTEREST}

The author confirms that this article content has no conflict of interest.

\section{ACKNOWLEDGEMENTS}

Declared none.

\section{REFERENCES}

[1] Y. B. Cao, W. P. Gao, and Y. Yang, "The real-time simulation of two-capacity water tank based on equation of state model", Computers and Applied Chemistry, vol. 31, pp. 244-246, Feb. 2014.

[2] B. Kumar, and R. Dhiman, "Optimization of PID controller for liquid level tank system using intelligent techniques", Canadian Journal on Electrical and Electronics Engineering, vol. 2, pp. 531535, Mar. 2011.

[3] F. Aslam, and M. Zeeshan, "An implementation and comparative analysis of PID controller and their auto tuning method for three tank liquid level control", International Journal of Computer Applications, vol. 21, pp. 42-45, Aug. 2011.
[4] X. P. Li, "Modeling of Liquid Level Control System and Study of its Control Algorithms", M.S. thesis, Harbin Institute of Technology, Harbin, Heilongjiang, China, 2007.

[5] Y. F. Xu, G. H. Huang, and Z. S. Jiang, "The research and development of automatic three-tank liquid level control experiment system", Computers and Applied Chemistry, vol. 30, pp. 1203-1206, Oct. 2013.

[6] H. Kala1, D. Deepakraj, P. Gopalakrishnan, P. Vengadasan, and M. Karum bad Iyyar, "Performance evaluation of fuzzy logic and PID controller for liquid level process", International Journal of Innovative Research in Electrical, Electronics, Instrumentation and Control Engineering, vol. 2, pp. 1311-1314, Mar. 2014.

[7] M. Rahmat, and S. Rozali, "Modeling and controller design for a coupled tank liquid level system: analysis and comparison", Journal Teknologi, vol. 48, pp. 113-141, Jun. 2008.

[8] T. Zhao, P. Li, and J. Cao, "Study of interval type-2 fuzzy controller for the twin-tank water level system", Chinese Journal of Chemical Engineering, vol. 20, pp. 1102-1106, Jun. 2012.

[9] W. Chen, and G. Wu, "Modeling of nonlinear two-tank system and model predictive control", Journal of System Simulation, vol. 18, pp. 2078-2085, Aug. 2006.

[10] B. M. Chen, S.S. Ge, and B. Ren, "Robust attitude control of helicopters with actuator dynamics using neural networks", IET Control Theory and Applications, vol. 4, pp. 2837-2854, Dec. 2010.

This is an open access article licensed under the terms of the Creative Commons Attribution Non-Commercial License (http://creativecommons.org/licenses/bync/4.0/) which permits unrestricted, non-commercial use, distribution and reproduction in any medium, provided the work is properly cited. 